\title{
Balloon in the left ventricular outflow tract: A surgical technique for the calcified unclampable aorta with aortic insufficiency
}

\author{
Amit Pawale, MD, FRCS, ${ }^{\mathrm{a}}$ Aaron Weiss, MD, ${ }^{\mathrm{a}}$ Alexander Mittnacht, MD, ${ }^{\mathrm{b}}$ and Paul Stelzer, MD, ${ }^{\mathrm{a}}$ \\ New York, NY
}

Calcified ascending aorta with severe aortic insufficiency (AI) is a unique problem. Clamping a heavily calcified aorta carries a major risk of stroke. To achieve adequate systemic cooling for deep hypothermic circulatory arrest (DHCA) without aortic clamping in the setting of severe $\mathrm{AI}$ is a difficult challenge. In such a scenario, if ventricular fibrillation occurs, the left ventricle (LV) can distend despite the LV vent, which is typically placed through the right superior pulmonary vein (RSPV). This can lead to subendocardial ischemia and myofibrillar disruption, with subsequent myocardial dysfunction. Ventricular fibrillation can be delayed or sometimes avoided by gradual cooling. ${ }^{1}$ Retrograde warm blood perfusion through the coronary sinus to keep the heart beating has been described. ${ }^{2}$ A pulmonary arterial vent can be placed in addition to that in the $\mathrm{RSPV}^{3}$; however, if and when there is excessive LV distention, one is forced to arrest the circulation before the desired temperature has been achieved. ${ }^{4} \mathrm{We}$ describe a technique to prevent $\mathrm{LV}$ distention by using an inflated balloon in the $\mathrm{LV}$ outflow tract (LVOT), thereby allowing continuation of systemic cooling and coronary perfusion on cardiopulmonary bypass until the goal temperature for DHCA has been achieved.

\section{CLINICAL SUMMARY Patient 1}

A 74-year-old man with symptomatic severe AI and 2-vessel in-stent coronary artery stenosis had a calcified ascending aorta. At operation, a clean spot to cannulate was located by means of epiaortic ultrasonography in the lower ascending aorta anteriorly, and cardiopulmonary bypass was initiated. The LV vent was placed through the RSPV. Gradual systemic cooling was begun. When the heart fibrillated, flow was reduced and a 16F Foley catheter with a stainless steel stylet was passed through a purse-

\footnotetext{
From the Departments of Cardiothoracic Surgery ${ }^{\mathrm{a}}$ and Anesthesia, ${ }^{\mathrm{b}}$ Mount Sinai Medical Center, New York, NY.

Disclosures: Alexander Mittnacht reports lecture and consulting fees from Casmed and consulting fees from Abiomed. Paul Stelzer reports consulting fees from Cryolife. All other authors have nothing to disclose with regard to commercial support. Received for publication Sept 3, 2013; revisions received Oct 21, 2013; accepted for publication Oct 31, 2013; available ahead of print Dec 13, 2013.

Address for reprints: Paul Stelzer, MD, 1190 Fifth Ave, Box 1028, New York, NY 10029 (E-mail: paul.stelzer@mountsinai.org).

J Thorac Cardiovasc Surg 2014;147:1097-8

$0022-5223 / \$ 36.00$

Copyright (C) 2014 by The American Association for Thoracic Surgery

http://dx.doi.org/10.1016/j.jtcvs.2013.10.045
}

string suture at another clean spot on the ascending aorta just proximal to the aortic cannulation site and guided through the aortic valve into the LV (Figure 1, B). The stylet was removed, and under transesophageal echocardiographic (TEE) guidance the balloon was inflated with $15 \mathrm{~mL}$ normal saline solution (Figure 1,C) and was gently pulled into the LVOT to occlude the aortic valve (Figure 2, $A$ ). Gentle upward traction was maintained on the balloon. The TEE demonstrated coronary ostial flow (Figure 2, C) and no AI (Figure 2, B) as systemic flow was increased to full. Cooling was continued to achieve the target temperature $\left(24^{\circ} \mathrm{C}\right)$ without $\mathrm{LV}$ distention. After graft replacement of the ascending aorta under DHCA, coronary bypass grafting and aortic valve replacement were performed.

\section{Patient 2}

A 67-year-old man had severe mitral regurgitation, moderate AI, chronic atrial fibrillation, severe pulmonary hypertension, and severe ascending aortic calcification. Cardiopulmonary bypass was instituted as in the case of patient 1, the RSPV vent was placed, and systemic cooling was initiated. A $12 \mathrm{~F}$ Reliant stent graft balloon catheter (Medtronic, Inc, Minneapolis, Minn) was inserted through another proximal ascending aortic soft spot with the Seldinger technique and passed through the aortic valve into the LV. When the heart fibrillated, the balloon was inflated with $20 \mathrm{~mL}$ saline solution, pulled up into the LVOT, and held in place, stopping any AI with maintained systemic and coronary perfusion. DHCA was achieved at $24^{\circ} \mathrm{C}$. After graft replacement of the ascending aorta was done under DHCA, cryomaze, mitral valve repair, left atrial appendage excision, aortic valve replacement, and septal myectomy were performed.

\section{RESULTS}

Both patients were extubated on postoperative day 1 and stayed in intensive care for less than 2 days. They were discharged home on postoperative days 6 and 8, respectively. There were no complications attributable to the technique in either case; however, our experience is currently limited to these 2 cases.

\section{DISCUSSION}

This is a simple, effective, and reproducible technique. Although the Foley stylet is no longer commonly used in 


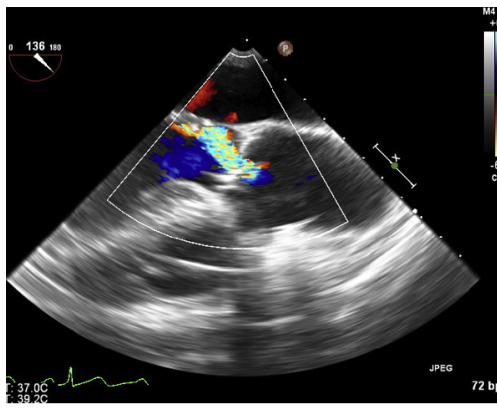

A

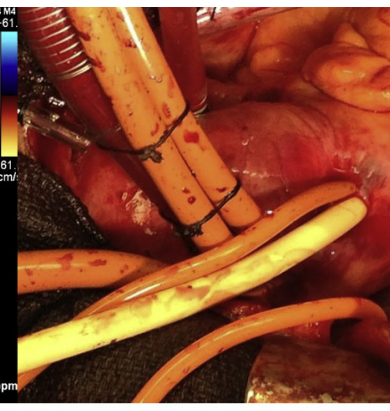

B
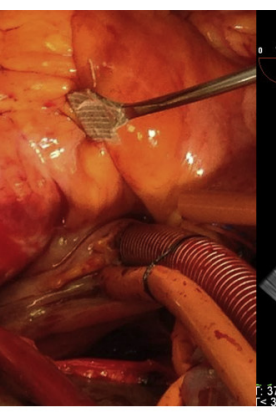

C

FIGURE 1. Patient 1: A, Transesophageal echocardiography showing severe aortic insufficiency. B, Intraoperative view shows a $16 \mathrm{~F}$ Foley catheter inserted through the ascending aorta. C, Transesophageal echocardiography showing the inflated balloon in the left ventricular apex.

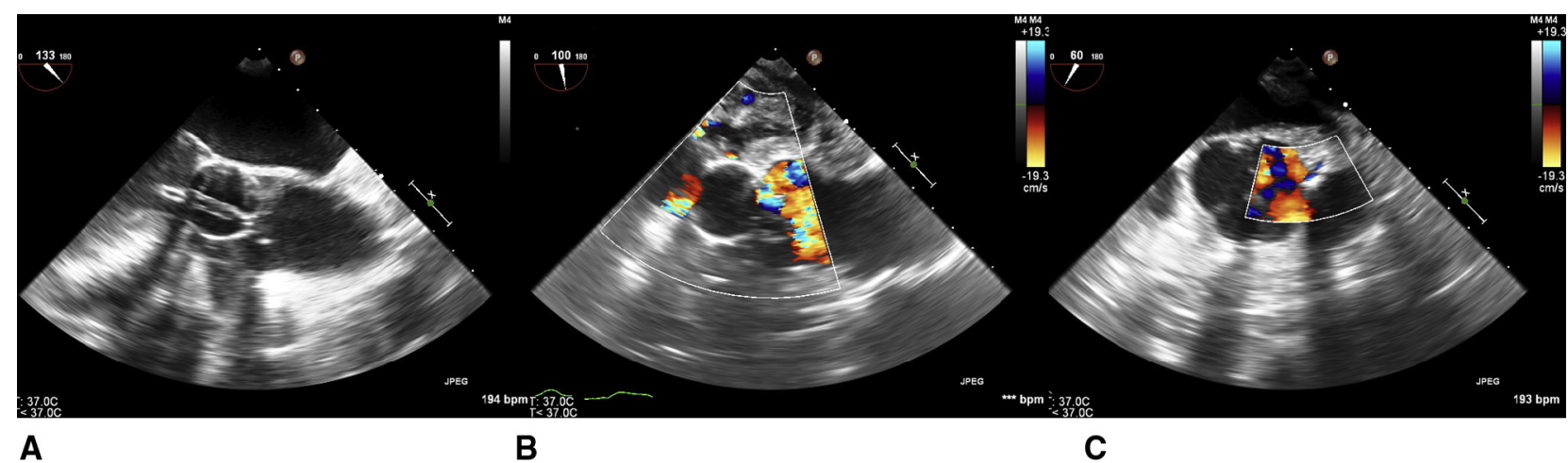

FIGURE 2. Patient 1: A, Transesophageal echocardiography showing the inflated balloon in the left ventricular outflow tract. B, Transesophageal echocardiography showing no aortic insufficiency when the inflated balloon occludes the left ventricular outflow tract. C, Transesophageal echocardiography showing the presence of blood flow in the left main stem when the inflated balloon occludes the left ventricular outflow tract.

urology and might not be easily available, the stent graft balloon catheter is readily available and has a much smaller diameter. Potential complications include LV perforation, conduction abnormalities, ischemia of the LVOT, and anterior mitral leaflet damage. These can be avoided by gentle manipulation of the catheter and the balloon under careful TEE guidance. This technique requires the presence of a soft spot on the ascending aorta (which is usually available) to insert the balloon catheter. The unknown risk of stroke when using a soft spot in the aorta to pass the catheter is probably insignificant relative to the risk of clamping a heavily calcified aorta, even if the clamp is applied carefully under direct vision. ${ }^{5}$ In the absence of such a spot, a peripheral arterial approach could be used; however, it would carry a higher stroke risk because of the atherosclerotic burden of an unclampable ascending aorta. Expert TEE guidance is mandatory.

\section{References}

1. Byrne JG, Aranki SF, Cohn LH. Aortic valve operations under deep hypothermic circulatory arrest for the porcelain aorta: "no-touch" technique. Ann Thorac Surg. 1998;65:1313-5.

2. Khalpey Z, Dekkers RJ, Nauta FJ, Shekar P. Warm beating heart with deep hypothermic circulatory arrest: a technique for an unclampable aorta with aortic valve regurgitation. J Thorac Cardiovasc Surg. 2012;144:731-2.

3. Aranki SF, Nathan M, Shekar P, Couper G, Rizzo R, Cohn LH. Hypothermic circulatory arrest enables aortic valve replacement in patients with unclampable aorta. Ann Thorac Surg. 2005;80:1679-86; discussion 1686-7.

4. Gillinov AM, Lytle BW, Hoang V, Cosgrove DM, Banbury MK, McCarthy PM, et al. The atherosclerotic aorta at aortic valve replacement: surgical strategies and results. J Thorac Cardiovasc Surg. 2000;120:957-63.

5. Takami Y, Tajima K, Terazawa S, Okada N, Fujii K, Sakai Y. Sakai. Safer aortic crossclamping during short-term moderate hypothermic circulatory arrest for cardiac surgery in patients with a bad ascending aorta. J Thorac Cardiovasc Surg. 2009; 137:875-80. 